\title{
Wind Energy Conversion System under a Supervisor Deterministic Finite State Machine
}

\author{
C. Viveiros ${ }^{1,2,3}$, R. Melício ${ }^{1,2}$ SM IEEE, J.M. Igreja ${ }^{3}$, V.M.F. Mendes ${ }^{2,3}$ \\ ${ }^{1}$ IDMEC, Instituto Superior Técnico, Universidade de Lisboa, Lisbon, Portugal \\ ${ }^{2}$ Departamento de Física, Escola de Ciências e Tecnologia, Universidade de Évora, Évora, Portugal \\ ${ }^{3}$ ADEEEA, ISEL-Instituto Superior de Engenharia de Lisboa, Instituto Politécnico de Lisboa, Lisbon, Portugal \\ \{cviveiros, jigreja ,vfmendes\}@deea.isel.ipl.pt; ruimelicio@gmail.com
}

\begin{abstract}
This paper presents a simulation of an onshore energy conversion system connected to the electric grid and under a strategy of a supervisor control based on deterministic version of a finite state machine. The simulation is planned to address an analysis on performance due to the action of the supervisor. The supervisor is included at the higher level, having the objective of analyzing the operational states according to the wind speed. The energy conversion system is equipped with a doubly-fed induction generator and a variable speed variable pitch wind turbine. The analysis is carried by computer simulations and the obtained results allow assessment to the performance of the system. A comparison of the wind energy conversion system performance with or without the supervisor is carried out in order to access the influence of the strategy on the performance.
\end{abstract}

Keywords-wind energy; supervisor, finite state machines; operational states.

\section{INTRODUCTION}

Decrease in external energy dependence and increase in efficiency of usage of energy are political objectives of which most countries are committed. Mitigation of carbon intensity in the economy is a political objective in order to achieve sustainable development. Exploitation of endogenous renewable energy sources is one way to achieve a decrease in external energy dependence and carbon intensity. Particularly, wind energy exploitation is quite important as shown by the 2014 half-year report of the world wind energy association, stating that: the worldwide wind power capacity has reached approximately $336 \mathrm{GW}$ by the end of June 2014 [1].

The exploitation of wind energy has been pursued with a significant research and development on technology of wind energy conversion system (WECS). Research and development intended for this technology has been carried out in order to allow a reduction on investment per unit of power capacity and an improvement on the quality of energy injected into the electric grid. The technology of WECS having variable-speed and variable-pitch (VSVP) has been reported as having enhanced performance due to advantageous energy capturing when compared with other conventional technology for WECS [2,3]. Also, amongst the electrical generators available for equipping WECS having VSVP, the option for the doubly-fed induction generator (DFIG) stands out in industry and became the mainstream choice [4,5]. Advanced control techniques on the DFIG have been researched and developed with the objective of enhancing the quality of energy injected into the electric grid [6]. The WECS having VSVP are equipped with power electronic converters in order to conveniently interface the frequency imposed by the mechanical movement of the rotor with the electric grid frequency. The interface enables the operation of the system over an extended wind speed range, changing the rotor speed in order to implement a procedure for maximization of energy conversion $[7,8]$.

The state of operation of a WECS can be classified according with the wind speed range into four regions of power operation [9-11]. Region I: where the wind speed is less than the cut-in speed, typically $5 \mathrm{~m} / \mathrm{s}$, WT is in shut down. Region II: where the wind speed is not less than the cut-in speed and is less than the rated wind speed, typically $13 \mathrm{~m} / \mathrm{s}$. The aim in Region II is to maximize the capture of the kinetic energy from the wind. Region III: where the wind speed is not less than the rated wind speed and is lower than the cut-out speed. The aim in Region III is to operate at nominal generator speed, and pitch control is used to conveniently curtail the capture of kinetic energy from the wind. Region IV: where the wind speed is not less than the cut-out speed, typically above $25 \mathrm{~m} / \mathrm{s}$, the turbine is in shut down for safety purpose. The operating regions Region II and Region III are the ones that need more suitable involvement of control and supervision action $[12,13]$. The challenge for Region II is to design control and supervision to maximize power output. While, the challenge for Region III is to curtail the capture of wind energy in order to operate at the nominal power. The curtailment is achieved by control of the pitch angle and at the same time not only minimizing the turbine load, but also ensuring the reliability of WECS. Hence the controller needs to access in due time the rotor speed and pitch angle under the unpredictable character of the wind energy.

The performance due to the capture of wind energy is an important issue and has been dealt not only by research on turbine design and advanced control strategy, but also by condition monitoring using a supervisor. Research have been addressing this issue, for instances: [14] provides a general review, a classification of wind turbine condition monitoring methods and techniques with a focus on trends and future challenges; [15] provides basic ideas of how a supervisory control and data acquisition system contributes to a high reliability and availability on offshore wind farms. 
This paper is about the influence of a supervisor based on a deterministic version of finite state machines (FSM) to be applied on a WECS having VSVP and equipped with DFIG. The supervisor has the objective of analyzing the operational states. A proportional integral control is used for achieving the convenient maneuver over Region II or Region III. Hence, the strategy for the supervisor has to deliver optimal power extraction and output power at the nominal power on Region II and Region III, respectively. The strategy is simulated using the wind turbine benchmark model developed by Odgaard [16]. The simulation is carried out under the Matlab/Simulink in order to access the efficacy of the strategy.

The following sections are organized as follows: Section II is about the modeling followed for the WECS equipped with VSVP and with DFIG; Section III presents the conventional controller and the strategy for the supervisor; Section IV presents the carried out results of the simulations. Finally, conclusions are presented in Section V.

\section{WECS MODELING}

The mathematical model for the WECS in this paper is based on the standard model reported in [16]. This standard is described by a block diagram composed of four blocks, describing the models for the: control, blade and pitch, drive train and electric generator. This section describes the ones to be considered, i.e., the last three models.

\section{A. Blade and Pitch Model}

This model combines the aerodynamic with blade and pitch models. The aerodynamic torque is given by:

$$
\tau_{r}(t)=\frac{\rho \pi R^{3} C_{p}(\lambda(t), \beta(t)) v_{w}(t)^{2}}{2}
$$

where $\rho$ is the air density, $C_{p}(\lambda(t), \beta(t))$ is the power coefficient, which is a function of the tip speed ratio and the pitch angle, respectively, $R$ is the radius of the blades. The tip speed ratio is given by:

$$
\lambda(t)=\frac{\omega_{r}(t) R}{v_{w}(t)} .
$$

From (2), the change in the wind speed can lead to two consequences:

- if the mechanical speed is constant, then $\lambda(t)$ will change, leading to a consequent change in $C_{p}$, hence in the power capturing;

- $\quad$ if the mechanical speed is suitably adjusted, then $\lambda(t)$ can be held at a reference point and as a result $C_{p}$ can be kept at a desired value.

The $C_{p}$ function used in [17] and in this paper is given by:

$$
C_{p}(\lambda, \beta)=0.73\left(\frac{151}{\lambda_{i}}-0.58 \beta-0.002 \beta^{2.14}-13.2\right) e^{\frac{-18.4}{\lambda_{i}}}
$$

where $\lambda_{i}$ is given by:

$$
\lambda_{i}=\frac{1}{\frac{1}{(\lambda-0.02 \beta)}-\frac{0.003}{\left(\beta^{3}+1\right)}} .
$$

The pitch angle equation is a second order differential equation given by:

$$
\ddot{\beta}(t)=-\omega_{n}^{2} \beta(t)+\omega_{n}^{2} \beta_{r}(t)-2 \xi \omega_{n}(t) \dot{\beta}(t) .
$$

\section{B. Drive Train Model}

The mathematical model for drive train is a two-mass model. The first mass is associated with the inertia of the turbine blades, hub and low-speed shaft inertia. The moment of inertia for the first mass is $J_{r}$. The second mass is associated with the generator inertia and high-speed shaft. The moment of inertia for the second mass is $J_{g}$. The low-speed and highspeed shafts are connected by a gear box with a ratio $N_{g}$. The torsion shaft stiffness is $K_{d t}$ and torsion shaft damping is $B_{d t}$. The angular deviation due to the damping and stiffness coefficients between the turbine and the generator is $\theta_{\Delta}(t)$. The two-mass drive train is shown in Fig. 1.

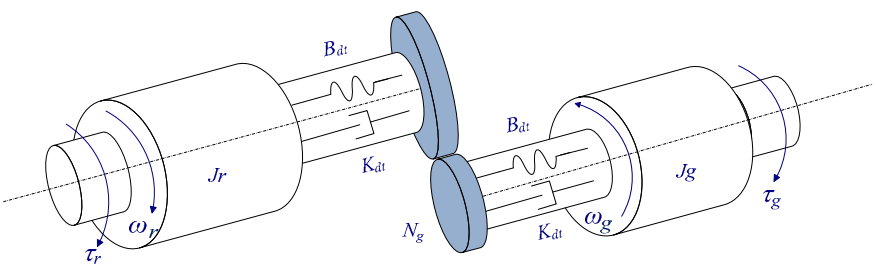

Fig. 1. Two-mass drive train.

The two-mass drive train model is expressed by the state vector equation given by:

$$
\dot{x}_{d t}=A x_{d t}+B u_{d t}
$$

where

$$
\begin{aligned}
& x_{d t}=\left(\begin{array}{lll}
\omega_{r} & \omega_{g} & \theta_{\Delta}
\end{array}\right)^{T}, \quad u_{d t}=\left(\begin{array}{ll}
\tau_{r} & \tau_{g}
\end{array}\right)^{T} \\
& A=\left(\begin{array}{ccc}
-\frac{B_{d t}-B_{r}}{J_{r}} & \frac{B_{d t}}{N_{g} J_{r}} & -\frac{K_{d t}}{J_{r}} \\
\frac{\eta_{d t} B_{d t}}{N_{g} J_{g}} & -\frac{\frac{1}{g}_{g}}{J_{g}} & \frac{\eta_{d t} K_{d t}}{N_{g} J_{g}} \\
1 & -\frac{1}{N_{g}} & 0
\end{array}\right) ; B=\left(\begin{array}{cc}
\frac{1}{J_{r}} & 0 \\
0 & -\frac{1}{J_{g}} \\
0 & 0
\end{array}\right)
\end{aligned}
$$

C. Generator Model

The model for the generator and the power converter is described by the state equation given by:

$$
\dot{\tau}_{g}(t)=-\alpha_{g c} \tau_{g}(t)+\alpha_{g c} \tau_{g, r}(t)
$$


where $\alpha_{g c}$ is a first order constant and $\tau_{g, r}$ is the reference torque of the generator. The power of electric generator is given by:

$$
P_{g}(t)=\eta_{g} \omega_{g}(t) \tau_{g}(t)
$$

where $\eta_{g}$ is the efficiency of the generator.

\section{CONTROL AND SUPERVISION}

The control operates in Region II and in Region III with different objectives. These regions are located in the regions of power operation as shown in Fig. 2.

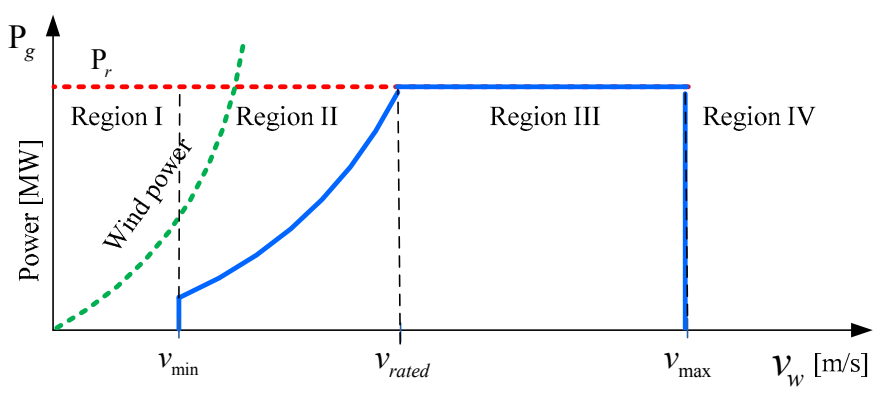

Fig. 2. Regions of power operation [8].

Region II: the objective is not only to extract maximum energy as possible from the wind power, but also to reduce the oscillation on the drive train, applying torque control. This objective is achieved by setting the reference for the pitch angle equal to zero and the tip speed ratio at the optimal value for achieving optimal energy capturing. The rotor speed is adjusted to the speed given by:

$$
\omega_{r e f}(t)=\frac{\lambda_{o p t}(t) v_{w}(t)}{R} .
$$

The optimal electric generator torque is given by:

$$
\tau_{g, r}(k)=K_{o p t}\left(\frac{\omega_{r e f}(k)}{N_{g}}\right)^{2}
$$

where

$$
K_{o p t}=\frac{1}{2} \rho A R^{3} \frac{C p_{\max }}{\lambda_{o p t}^{3}}
$$

and where $\lambda_{\text {opt }}$ is the optimal point for achieving maximum $C_{P}$ and $A$ is the area swept by the blades.

Region III: the objective is to keep the output power at rated power through pitch control, varying the pitch angle according to the error between nominal speed and the output generator speed. The pitch reference and generator torque reference should be adjusted at the same time and the latter is given by:

$$
\tau_{g, r}(k)=\frac{P_{r}(k)}{\eta_{g} \omega_{g}(k)}
$$

The switching between these two regions, i.e., Region II and Region III, are procedure determined by the electric generator power, $P_{g}$, and the generator speed, $\omega_{g}$, described as:

if $<<$ in Region II, $P_{g}>P_{r}$ and $\omega_{g}>\omega_{n o m}>>$, then go to Region III

else if $<<$ in Region III and $\omega_{g}<\omega_{\text {nom }}-\omega_{\Delta}>>$, then

end if

go to Region II

The non-null threshold $\omega_{\Delta}$ is required in order to enable preventing sudden switches from Region III and Region II.

\section{A. Proportional Integral Controller}

The standard model [16] for the wind turbine followed in this paper is composed of the four blocks: control, blade and pitch, drive train and electric generator. The functional model used in this paper for the wind turbine under the supervisor control is the block diagram shown in Fig. 3.

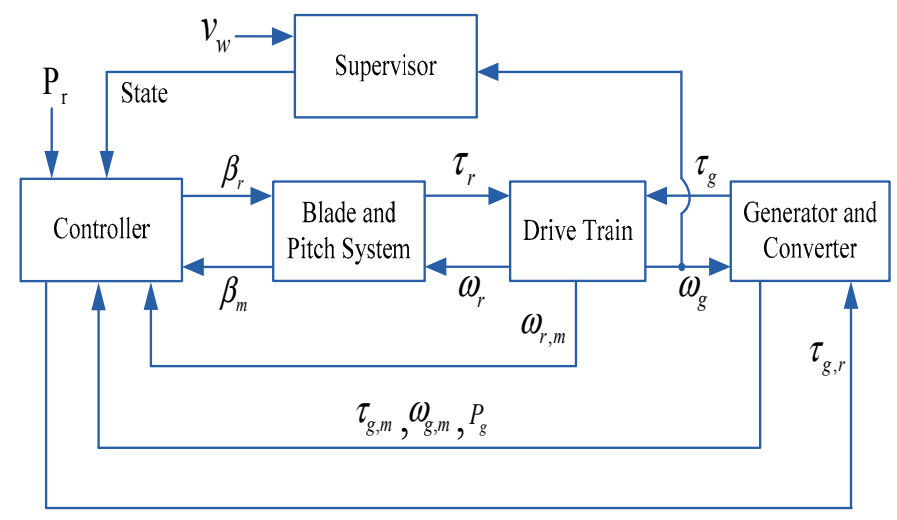

Fig. 3. Wind turbine under supervisor control.

The variables shown in Fig. 3 are as follow:

$$
\begin{array}{llll}
\tau_{g}[\mathrm{Nm}] & \text { generator torque } & \tau_{r}[\mathrm{Nm}] & \text { rotor torque } \\
v_{w}[\mathrm{~m} / \mathrm{s}] & \text { wind speed } & \omega_{r}[\mathrm{rad} / \mathrm{s}] & \text { rotor speed } \\
\omega_{g}[\mathrm{rad} / \mathrm{s}] & \text { generator speed } & \beta\left[^{\circ}\right] & \text { pitch angle } \\
P_{g}[\mathrm{~W}] & \text { generator power } & P_{r}[\mathrm{~W}] & \text { rated power }
\end{array}
$$

where $r$ is a subscript of references for rotor quantities and $m$ is the subscript for measurement values. The controller is implemented by a conventional proportional integral (PI) one. Discretization is used by differentiating the time continuous formula of the PI control and further applying the backward differentiation method to obtain a discrete-time formula. The PI control discrete-time formula is given by:

$$
\begin{aligned}
& u(k)=u(k-1)+k_{p} e(k)+\left(k_{i} T_{s}-k_{p}\right) e(k-1) \\
& e(k)=\omega_{g}(k)-\omega_{\text {nom }}(k)
\end{aligned}
$$

where $\omega_{\text {nom }}$ is the nominal value for the turbine speed, $K_{p}$ and $K_{i}$ are the proportional gain and the integral gain of the control, respectively, and $u(k)=\beta_{r}(k)$. 


\section{B. Supervisor}

The WECS supervisor is based on FSM also known by finite-state automaton or state machine. This machine is a mathematical model of computation to conveniently schedule the operational states of a process. The states are such as: start, production and stop. The machine is in only one state at a time and can change from one state to another when initiated by a triggering event or condition called a transition. The machine is a set of: behavior states, transitions that define the transit between states and rules or conditions to be fulfilled in order to enable a transition. The specification of a machine is given by the list of states and the triggering condition for transitions. The FSM is described by a quintuple model $[18,19]$ given by:

$$
F S M=\left(\Sigma, Q_{f}, \partial, q_{0}, Q_{m}\right)
$$

where $\sum$ is the input alphabet, $Q_{f}$ is the finite set of states, $\partial=\sum \times Q$ is the transition function, $q_{0}$ is the initial state and $Q_{m}$ is the set of final states. The supervisor deterministic version of a FSM used in this paper has the state transition diagram shown by Fig. 4.

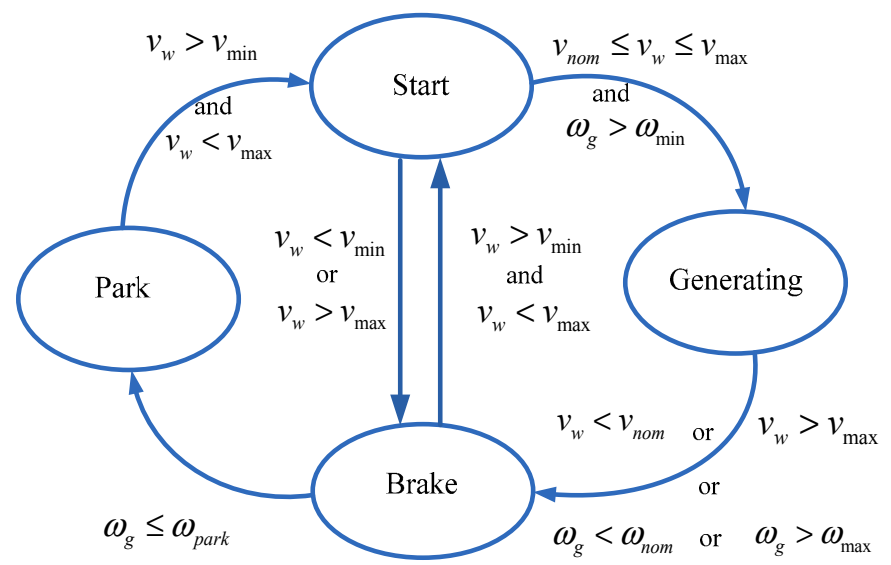

Fig. 4. Supervisor diagram for the wind turbine.

In Fig. 4, the operational states are park, start-up, generating and brake, typifying the regions of power operation as follow:

- $\quad$ Park is a state on Region I where the WECS is in shutdown and the generator is disconnected from the electric grid.

- $\quad$ Start-up is a state on Region II, where the wind speed is not less than the cut-in speed, the WECS should be started in order to capture energy from the wind power. The generator is connected to the electric grid, but not necessarily at rated power in the majority of the operation in Region II. This state can enter into the generating one or into the brake one according to the values for the wind speed and generator speed.

- Generating or power production state is a state on Region III, where the wind speed is not less than the rated wind speed and is lower than the cut-out speed. The operation is at nominal generator speed by conveniently curtailment of the capture of kinetic energy from the wind. The generator in this region is connected to the electric grid at rated power.

- Brake state is a state in Region IV where the WECS is in shutdown and the generator is disconnected from the electric grid. This state is achieved by conditions of exiting the generating state and the transition can be to the start-up or park state.

\section{Performance Assessment of the Controller}

The metrics used in the evaluation of the performance of the controller are the integral of time multiplied by the absolute value of the error (ITAE) and the integral of the square value (ISV). The ITAE is given by:

$$
\text { ITAE }=\int_{0}^{t_{f}} t|e(t)| d t
$$

The ISV is given by: $I S V=\int_{0}^{t_{f}} u^{2}(t) d t$

The control performances for the WECS without or with supervisor control are summarized in Table I.

TABLE I

CONTROL PERFORMANCE

\begin{tabular}{|c|c|}
\hline \multicolumn{2}{|c|}{ PI Controller } \\
\hline \multicolumn{2}{|c|}{ without Supervisor } \\
\hline ITAE & $1.210 \times 10^{15}(+0.5 \%)$ \\
\hline ISV & $6.054 \times 10^{6}(+5.00 \%)$ \\
\hline \multicolumn{2}{|c|}{ with Supervisor } \\
\hline ITAE & $1.2048 \times 10^{15}$ \\
\hline ISV & $5.7652 \times 10^{6}$ \\
\hline
\end{tabular}

Table I allows concluding that without the supervisor control, the switching between Region II and Region III is under the influenced of the switching procedure, implying a constrained performance due to the threshold $\omega_{\Delta}$. The adverse effect of the threshold is avoided by the supervisor control, enabling a further improvement on the performance.

\section{Simulation Results}

The mathematical model of the WECS equipped with a two-level power converter topology is used in the simulations. The simulations in order to compare the performance without or with the supervisor are carried out in Matlab/Simulink. The time horizon considered in the simulations is of $4500 \mathrm{~s}$, and the sampling time $T_{s}$ is of $0.01 \mathrm{~s}$. The WECS has a rated electric power of $4.8 \mathrm{MW}$ for a wind speed $v_{w}$ of $13 \mathrm{~m} / \mathrm{s}$, where $\omega_{\text {nom }}$ is $162 \mathrm{rad} / \mathrm{s}, \omega_{\Delta}$ is $15 \mathrm{rad} / \mathrm{s}$ and $\omega_{\max }$ is $200 \mathrm{rad} / \mathrm{s}$ [16]. The parameters $K_{P}$ and $K_{I}$ of the PI control have a value of 4 and 1, same as in [16]. The series for the wind speed used in the simulations are the ones given in [16], having amplitudes in the range of $7.5 \mathrm{~m} / \mathrm{s}$ to $22.5 \mathrm{~m} / \mathrm{s}$ between Region II and Region III, but an addition of white noise to the wind speed is considered in order to have an augment effect of intermittence of wind energy. The wind speed with the addition of white noise is shown in Fig. 5. 


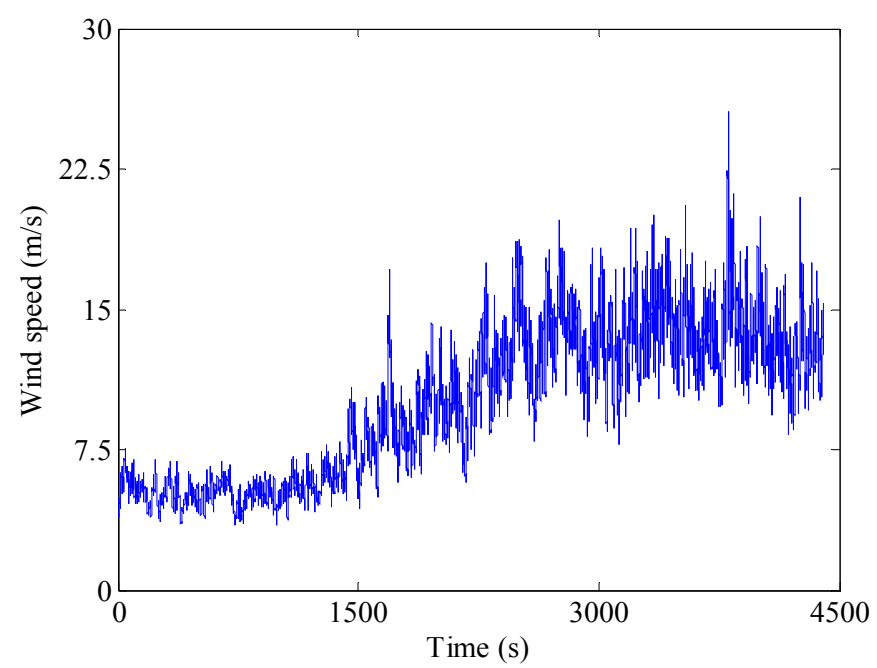

Fig. 5. Wind speed series added with white noise.

\section{A. Without supervisor}

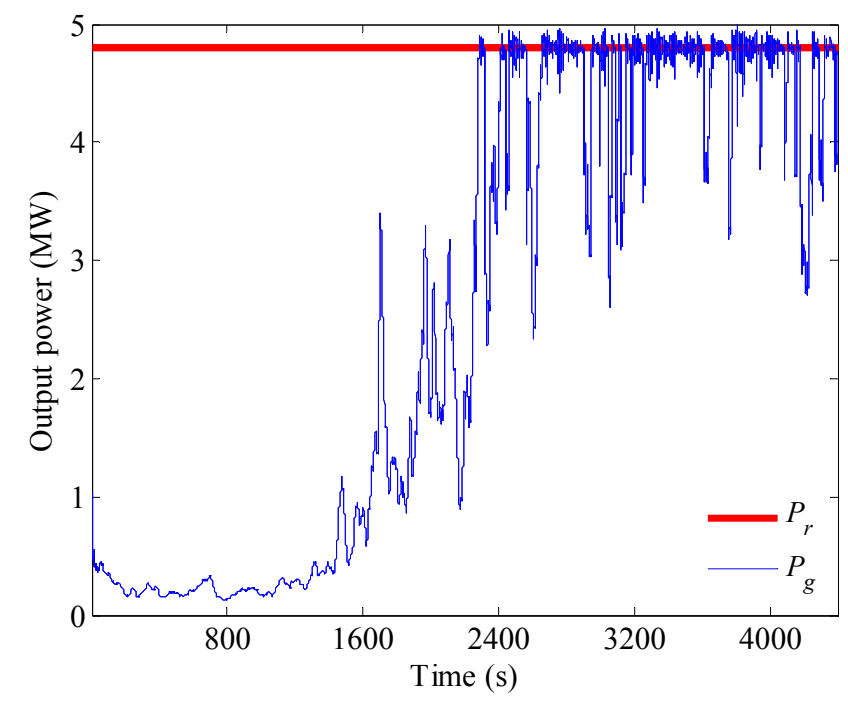

Fig. 6. Rated power, at red, and electric power without supervisor, at blue.

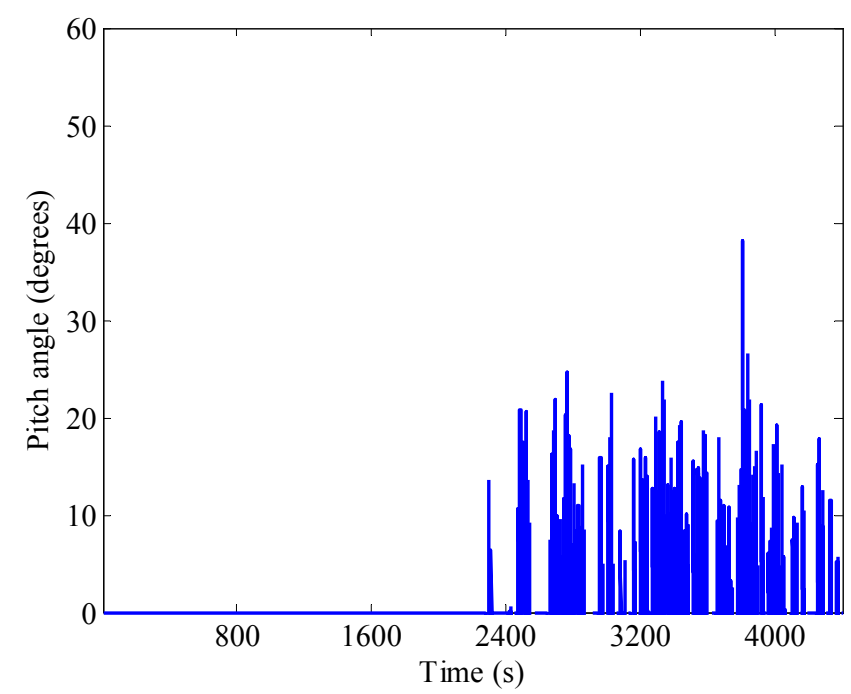

Fig. 7. Pitch angle without supervisor.

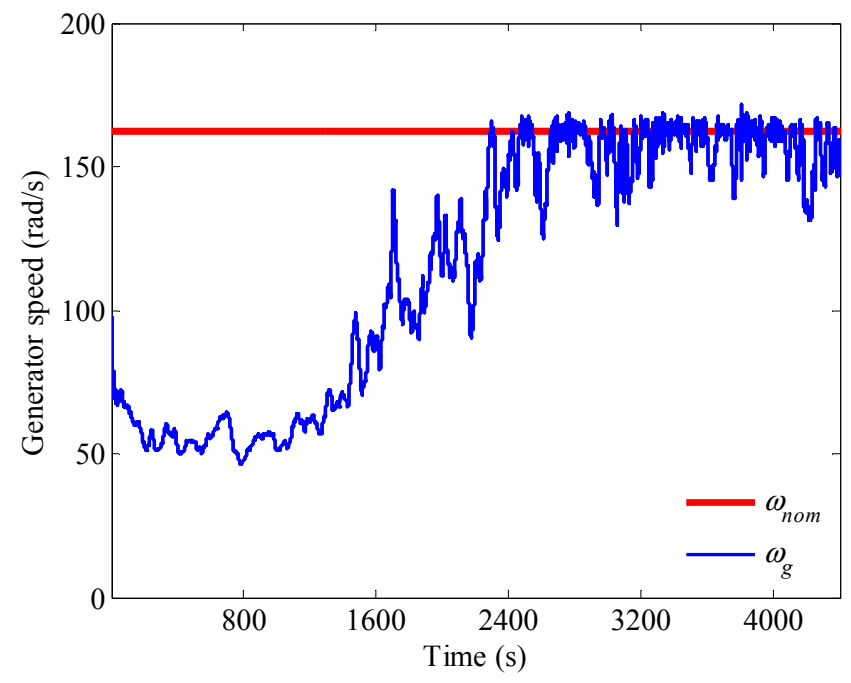

Fig. 8. Generator speed without supervisor.

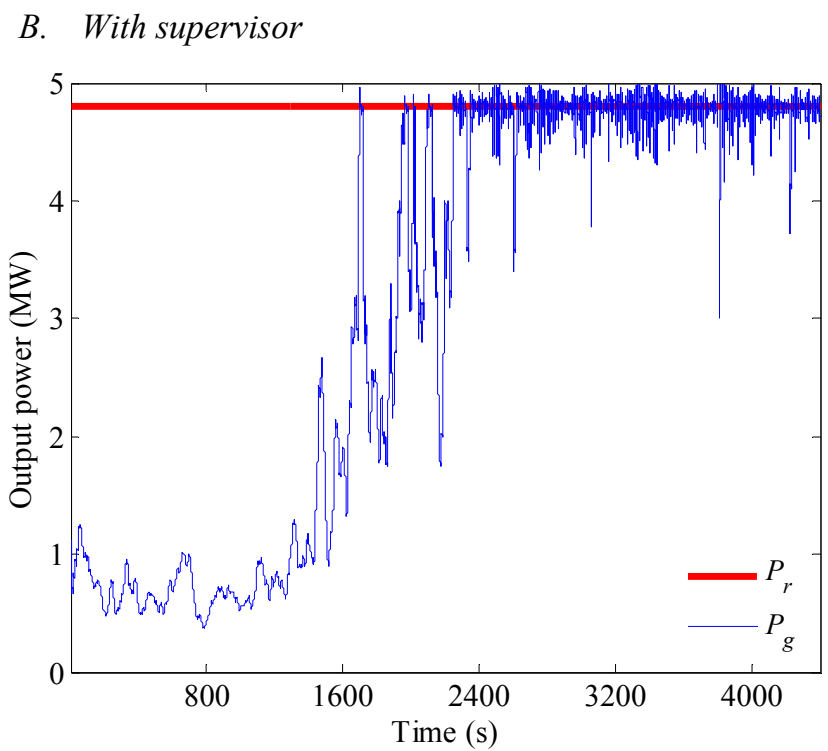

Fig. 9. Rated power, at red, and electric power with supervisor, at blue.

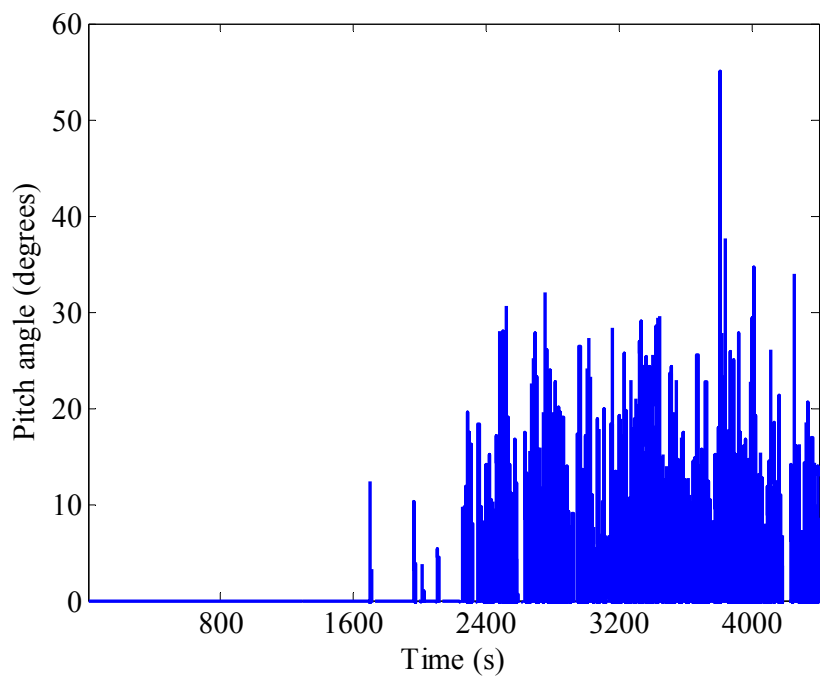

Fig. 10. Pitch angle with supervisor. 


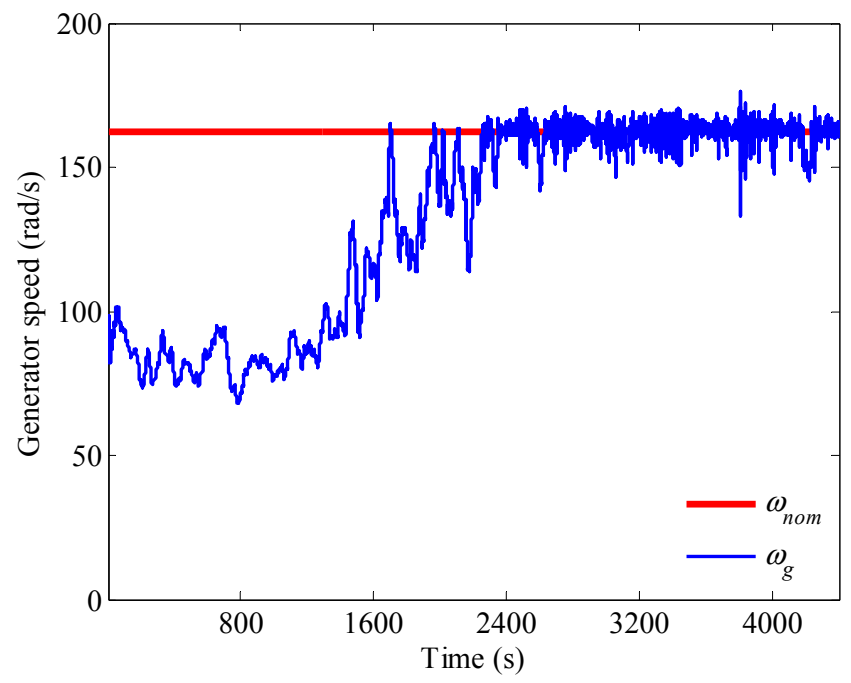

Fig. 11. Generator speed with supervisor.

Fig. 8 and Fig. 11 allow concluding as expected that the generator speed follows the nominal generator speed in both cases, i.e., without or with supervisor. But with the supervisor, the generator speed starts at a higher speed, influencing the subsequent electric power behavior as shown by a comparison between Fig. 6 and Fig. 9. Also, these two figures allow concluding that without the supervisor the output power reaches the reference power most of the times with wider variations. But with the supervisor the less wide variations on power reaching implies wider variations on the pitch angle as shown by a comparison between Fig. 7 and Fig. 10.

\section{CONCLUSIONS}

The mathematical model of a variable speed variable pitch wind turbine is addressed in order to include a deterministic supervisor based on FSM. The FSM is helpful in order to achieve a convenient implementation of operational states.

The comparison of the performance of the WECS without or with the supervisor allows to conclude that the output power reaches the reference power with less wide variations when in the presence of the supervisor. But with wider variations of the pitch angle, allowing for the supervisor improvement on the output power. The generator speed without the supervisor starts at a lower value than the one with the supervisor having a consequent improvement in the reaching output power.

The WECS performance without the supervisor is confined by the effect of the threshold to prevent sudden switches between Region III and Region II. With the supervisor this effect is disabled, improving the performance.

\section{ACKNOWLEDGMENT}

This work is funded by Portuguese Funds through the Foundation for Science and Technology-FCT under the: project LAETA 2015-2020, reference UID/EMS/50022/2013.

\section{REFERENCES}

[1] G. Gsänger, "World wind energy half-year report 2014," in Proc. 14th World Wind Energy Conference \& Exhibition, Jerusalem, Israel, 2015, pp. 1-8.

[2] A. Larsson, "Flicker emission of wind turbines during continuous operations," IEEE Transactions on Energy Conversion, vol. 17(1), pp. 114-119, August 2002.

[3] M. Garcia-Sanz, C.H. Houpis, Wind Energy Systems: Control Engineering Design, CRC Press, Taylor \& Francis, Boca Raton, 2012.

[4] R. Melício, V.M.F. Mendes, "Doubly fed induction generator systems for variable speed wind turbine," in Proc. 9th Spanish-Portuguese Congress on Electrical Engineering-9CHLIE, Marbella, Spain, 2005, pp. 161-164.

[5] K. Siraj, H. Siraj, M. Nasir, "Modeling and control of a doubly fed induction generator for grid integrated wind turbine," in IEEE International Power Electronics and Motion Control Conference and Exposition - PEMC 2014, Antalya, Turkey, 2014, pp. 901-906.

[6] K. Boulâam, A. Boukhelifa, "Fuzzy sliding mode control of DFIG power for a wind conversion system," in Proc. IEEE International Power Electronics and Motion Control Conference and Exposition-PEMC 2014, Antalya, Turkey, 2014, pp. 353-358.

[7] R. Melício, V.M.F. Mendes, J.P.S. Catalão, "Electrical grid integration and power quality studies of a variable-speed wind energy conversion system," in Proc. IEEE PowerTech 2009 Conference, Bucharest, Romania, 2008, pp. 1-6.

[8] R. Melício, V.M.F. Mendes, J.P.S. Catalão, "Power converter topologies and fractional-order controllers: wind energy applications," in Proc. 20th International Symposium on Power Electronics, Electrical Drives, Automation and Motion-SPEEDAM, Pisa, Italy, 2010, pp. 1334-1338.

[9] F. Bianchi, H. Battista, R. Mantz, Wind turbine control systems. London, UK, Springer-Verlag, 2007.

[10] K.E. Johnson, L.Y. Pao, M.J. Balas, L.J. Fingersh, "Control of variablespeed wind turbines: standard and adaptive techniques for maximizing energy capture," IEEE Control Systems, vol. 26, pp. 70-81, June 2006.

[11] T. Senjyu, R. Sakamoto, N. Urasaki, T. Funabashi, H. Fujita and H. Sekine, "Output power leveling of wind turbine generator for all operating regions by pitch angle control," IEEE Trans. Energy Conversion, vol. 21, no.2, pp. 467-475, June 2006.

[12] C. Viveiros, R. Melício, J.M. Igreja, V.M.F. Mendes, “Application of a Discrete Adaptive LQG and Fuzzy Control Design to a Wind Turbine Benchmark Model," in IEEE International Conference on Renewable Energy Research and Applications - ICRERA2013, Madrid, Spain, 2013, pp. 488-493.

[13] S. Rajendran, D. Jena, "Control of variable speed variable pitch wind turbine at above and below rated wind speed," Journal of Wind Energy, vol. 2014, pp. 1-14, October 2014.

[14] P. Tchakoua, R. Wamkeue, M. Ouhrouche, F. Slaoui-Hasnaoui, T. A. Tameghe G. Ekemb, "Wind turbine condition monitoring:state-of-the-art review,” Energies, vol. 7, pp. 2595-2630, April 2014.

[15] W. Yang, J. Jiang, "Wind turbine condition monitoring and reliability analysis by SCADA information," in IEEE International Conference on Mechanic Automation and Control Engineering - MACE2011, Hohhot, China, 2011, pp. 1872-1875.

[16] P.F. Odgaard, J. Stroustrup, M. Kinnaert, "Fault tolerant control of wind turbines: a benchmark model," IEEE Trans. Control Systems Technology, vol. 12, pp. 1168-1182, July 2013.

[17] R. Melício, V.M.F. Mendes, J.P.S. Catalão, "Wind turbines equipped with fractional-order controllers: stress on the mechanical drive train due to a converter control malfunction," Wind Energy, vol. 14, 13-25, 2010.

[18] C.G. Cassandras, S. Lafortune, Introduction to discrete event systems, Springer Science Business Media, New York, USA, 2000.

[19] C. Viveiros, R. Melício, J.M. Igreja, V.M.F. Mendes, "Performance assessment of a wind energy conversion system using a hierarchical controller structure," Energy Conversion and Management, vol. 93, pp. 40-48, March 2015. 